// MISCELLLÀNIA

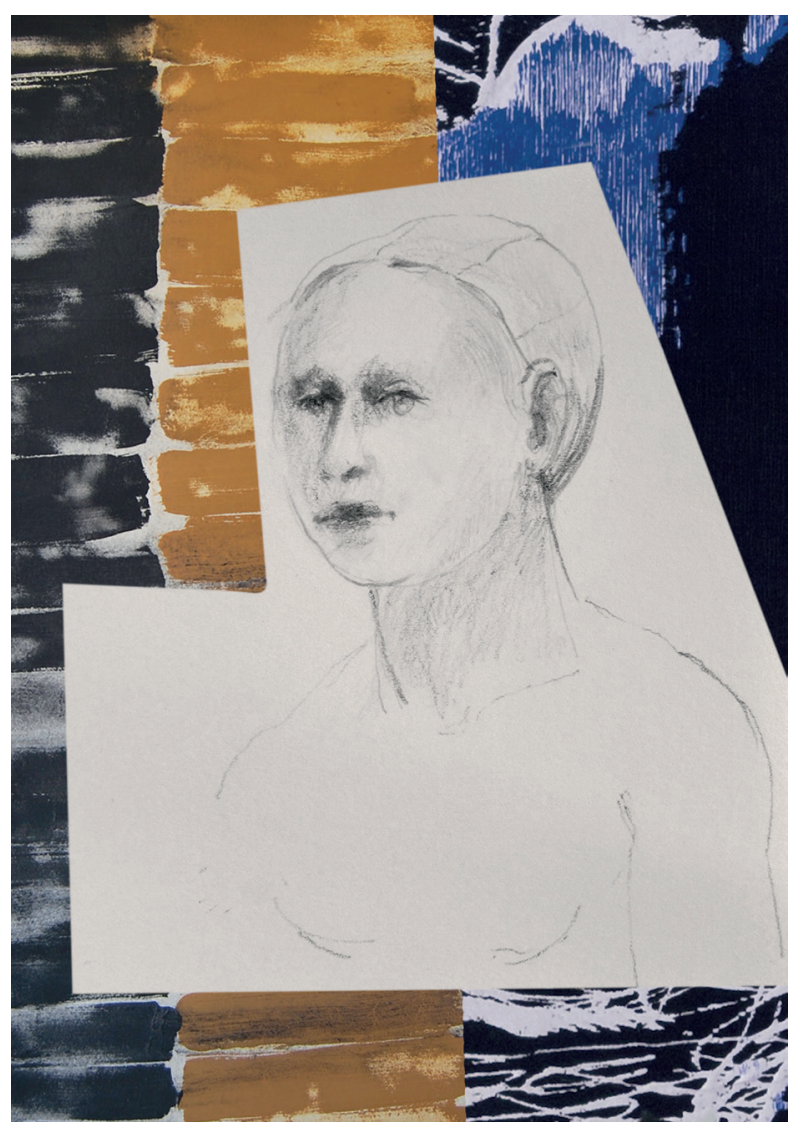


DAVID MARQUÉS

Altered hyperbolae V, 2020

Collage 


\title{
Falsament acusades d'adulteri. Llegendes historiogràfiques de temàtica recurrent a la Crònica universal de 1427
}

\section{[Women falsely accused of adultery. Historiographical legends based on a recurrent theme in the Crònica universal de 1427]}

\author{
Jacob Mompó Navarro \\ Universitat Catòlica de València
}

ORCID: 0000-0003-1178-9150 // jacob.mompo@ucv.es

Resum: Les falses acusacions d'adulteri han estat un tema recurrent al llarg de la historiografia. No de bades, la tradició judeocristiana, al llarg del temps ha descrit l'adulteri com un dels més greus pecats, en tant que ofensa al sagrament del matrimoni. En aquest sentit, una acusació d'adulteri, generalment cap a una víctima femenina, esdevenia una ofensa que s'havia de remeiar d'una o d'altra manera. Al llarg d'aquest treball tractarem el tema de l'adulteri a ulls del compilador de la Crònica Universal de 1427 i incorporarem les transcripcions de quatre llegendes en què una falsa acusació d'adulteri amenaçà la fama i virtuts de quatre grans dones: la virtuosa Lucrècia, l'emperadriu d'Alemanya, la reina calumniada i la comtessa de Tarragona.

Paraules clau: Adulteri, Historiografia, Crònica Universal, Llegendes.

AвstRACT: False accusations of adultery has been a frequent subject throughout history. Not surprisingly, the Judaeo-Christian tradition throughout time has described adultery as one of the most serious sins, as much as it offends the sanctity of marriage. In this sense, an accusation of adultery, usually directed at a female victim, was an offense that had to be dealt with in one way or another. Throughout this work we will deal with the subject of adultery in the same way as the compiler of the Universal Chronicle of 1427 and we will incorporate the transcriptions of four legends in which a false accusation of adultery threatens the fame and virtues of four great women: the virtuous Lucrezia, the Empress of Germany, the slandered Queen and the Countess of Tarragona.

KeYWords: Adultery, Historiography, Universal Chronicle, Legends.

Recepció: I4/03/2020. Acceptació: I0/04/2020. Publicació: 27/07/2020

REVISTA VALENCIANA DE FILOLOGIA / IV (2020) p. 207-24I / ISSN 0556-705X DOI IO.28939/RVF.V4.I34 


\section{Introducció}

Hom coneix amb el nom de Crònica universal de 1427 la crònica que conté el manuscrit 17.711 de la Biblioteca Nacional de Madrid. Aquest escrit historiogràfic va ser redactat durant la segona meitat del segle Xv per un cronista anònim que, molt probablement, devia ser valencià, si atenem a les característiques lingüístiques del text així com a la fixació de l'autor per fets esdevinguts a la ciutat i regne de València. L'esmentat manuscrit de la BNM s'havia considerat tradicionalment l'únic testimoni que ens havia pervingut del compendi historiogràfic. Això no obstant, l'Arxiu de la Catedral de València custodia un altre testimoni manuscrit de la crònica. Certament, el manuscrit 400 de l'ACV conserva uns pocs capítols de la part final de la crònica ${ }^{1}$ i va ser editat per Hinojosa (1979), que, sense conéixer que es tractava de la mateixa crònica, la va batejar amb el nom de Crònica de Pere Maça. Aquest altre testimoni ultrapassa la darrera notícia continguda al manuscrit de Madrid, esdevinguda l'any 1427, i avança uns pocs anys més, fins al 1430. Tanmateix, per la tradició historiogràfica del nom amb què la va batejar Miquel Coll i Alentorn (1972), preferim mantenir el nom de Crònica universal de $1427 .{ }^{2}$

L'obra narra la història del món conegut, des dels seus inicis fins als temps del cronista. Per tal de confeccionar el seu compendi historiogràfic, l'anònim autor es fonamenta, principalment, en els escrits de Vicenç de Beauvais, Pere Llombard, Martí de Troppau i, sobretot, Pere Comestor. Per a la redacció de la darrera secció de la crònica, el compilador sembla conéixer material historiogràfic provinent de Desclot i Muntaner, entre d'altres, per bé que la brevetat

\footnotetext{
* El present treball forma part del Proyecto PGC2018-097011-B-I00 «Biografías marginales: violencia, sexo, género e identidad. Edición y análisis de las fuentes documentales valencianas de la época foral», del Ministerio de Ciencia, Innovación y Universidades del Gobierno de España.

1 Les notícies que recull l'ACV Ms. 400 abasten des de la mort de Thomas Becket, arquebisbe de Canterbury (1171), fins a la derrota de la flota castellana contra l'exèrcit del Magnànim al cap de l'Aljub (1430).

2 Han treballat algun aspecte de la crònica Coll i Alentorn (1972: 49), Bohigas (2001: 470-478), Ferrando (1998), Cortadellas (2000: 10-14), Hirel-Wouts (2006: 284-285), Blasco Vallés (2010: 47-48) i Galdeano (2017: 205). L'estudi i edició de la Crònica universal de 1427, a Mompó Navarro (2019).
}

REVISTA VALENCIANA DE FILOLOGIA / IV (2020) p. I37-I 64

JACOB MOMPÓ NAVARRO

Falsament acusades d'adulteri / I 38 
amb què tracta els passatges finals dificulta la detecció de les fonts. D'altra banda, les notícies contingudes en els últims capítols de la crònica provenen, si no és que l'autor n'incorporara alguna a partir de la seua memòria, de diferents cronicons locals o reculls de memòries i notícies.

D'entre les històries i llegendes que el cronista convé d'incorporar al seu compendi, de tant en tant n'emergeix alguna en què l'ombra de l'adulteri plana sobre la protagonista del relat en qüestió. En altres ocasions - poques-el protagonista d'un relat amb presència de relacions adúlteres és un home; però en aquests casos el tractament és, generalment, diferent. En aquest sentit, si exceptuem, com veurem, les extirpacions d'ulls de la llegenda de Selentus, les llegendes que incorpora el nostre cronista solen ser benvolents si el protagonista és un home, fins a l'extrem que l'adulteri pot resultar un mitjà per a un bé major, com l'ascens en l'escalafó social. En canvi, les acusacions d'adulteri contra les protagonistes femenines de la crònica sempre busquen ultratjar la fama de la dama en qüestió i posar en dubte la seua virtuositat. En la majoria d'aquestes llegendes, l'honor de la dama serà defensat per un personatge masculí virtuós que a tal efecte s'enfrontarà, bé a un altre cavaller en una justa, bé a una multitud àvida de justícia. Feta aquesta consideració, hem de tenir en compte que el relat, sovint, frenètic del compilador de la crònica provoca la condensació de nombrosos elements en relats breus, brevíssims de vegades; i tanmateix, aquesta brevetat no representa cap inconvenient perquè hom puga apreciar-hi aquest extrem. En aquest treball incorporarem, en un primer apartat, aquells passatges més breus anecdòtics de vegades amb referències a l'adulteri, provinents en la seua majoria del relat bíblic, però també de l'antiguitat grecoromana, en tant que ens serviran per a emmarcar els diferents tractaments que rep l'adulteri a la crònica. En la segona part, inclourem la transcripció de les llegendes més importants que recull la crònica basades en la temàtica de l'adulteri, això és, la llegenda de la virtuosa Lucrècia, la de l'emperadriu d'Alemanya, la de la reina calumniada i la de la comtessa de Tarragona, quatre llegendes que tenen en comú una falsa acusació d'adulteri envers la seua protagonista.

REVISTA VALENCIANA DE FILOLOGIA / IV (2020) p. I37-I64 JACOB MOMPÓ NAVARRO Falsament acusades d'adulteri / I 39 


\section{Altres referències a l'adulteri en la crònica}

La prescripció de l'adulteri com a pecat, i alhora delicte, en les societats de l'Europa medieval i moderna té per fonament l'Antic Testament, que n'és explícit tant en la seua prohibició (Ex 20,14; Dt 5, 18), com en la seua punició (Lv 20, 10; Dt 22, 22). Especialment contundent és el llibre de Nombres quant a l'aplicació de les penes contra els adúlters així com pel que fa a l'esclariment dels fets. En aquest sentit, el nostre cronista transmet la seua versió del relat de Nombres, encabint-hi les diligències que s'havien d'efectuar per a comprovar la innocència de les dones acusades, sense proves, d'adulteri en l'apartat dedicat a la llei de la gelosia:

Aprés, donà Déu la ley de la gelosia. Hon gelosia pròpriament és amor que lo marit ha a la muller, per la qual no pot sostenir que altre hom se acoste a ella, e sospita que ha de adulteri. Donchs, si lo sperit de la gelosia se movia lo hom contra sa muller que la hagués en sospita que hagués fet mal ab altre que no u pogués provar, amenaven-la al prevere e offerien per aquella sis mesures d'ordi en farina. E no y scamparia oli dessús ni hi posava ensens, car sacrifici era de la gelosia. E lo prevere amenava-la al tabernacle davant Déu e posava-li en les mans una scudella de terra ab aygua clara e la oblació de la farina, de la qual prenia hun punyat e cremava-la sobre lo altar. E metia en l'aygua una poca de la pols del pahiment de l'altar e descobria-li lo cap e scrivia [en] una carta de pergamí prim lo nom de Déu, e fahia-li jurar lo nom de Déu que no es culpable en ço que.l marit la ha en sospita. E, si açò no basta al marit, lo prevere scriurà en la carta malediccions e dir-li ha: «Si tu no est malmirent, no•t noguen aquestes aygües amargoses. Mas, si est stada falsa e deslleal a ton marit, aquestes aygües maleytes entren en lo teu ventre e.l te fassen inflar e•t podresquen lo sagí a la part dreta». E respondrà la fembra e dirà: «Amèn, amèn». E lo prevere delirà la scriptura de la carta en l'aygua de la scudella e dar-li'n ha a beure. E depuix, lo prevere pendrà lo sacrifici de les mans de aquella e alçar-lo ha davant Déu e posar-lo ha sobre l'altar. E, si la fembra és culpable, inflaria lo ventre e podrir ha lo sagí, e morrà dins deu meses. E no li farà mal negú si no és culpable (f. 63r).

REVISTA VALENCIANA DE FILOLOGIA / IV (2020) p. I37-I64

JACOB MOMPÓ NAVARRO

Falsament acusades d'adulteri / I40 
Tot i que la Llei de Moisés explicitava que tant home com dona eren culpables en les relacions adúlteres, «tant l'adúlter com l'adúltera seran condemnats a mort» (Lv 20, 10), exemples com el que acabem de transcriure, en què és la dona qui sempre està sota sospita, són a bastament utilitzats en el relat bíblic, en particular, però en general al llarg de tota la literatura i historiografia europea de l'edat mitjana i moderna. En efecte, les principals llegendes que veurem en aquest escrit tenen com a protagonistes dones acusades falsament d'adulteri; i, per bé que en totes aquestes llegendes s'acaba provant, de manera més o menys tràgica, la innocència de l'acusada, sempre és l'honor de la dama allò que és objecte de judici, i habitualment és un home qui s'encarrega de demostrar la seua innocència.

En canvi, quan el protagonista que es veu immers en una relació adúltera és un home, generalment no és necessari cap judici probatori i l'assumpte es resol de diverses maneres, com ara el de la suposada bigàmia de Moisés. Segons el relat de l'Ėxode, Moisés estava casat amb na Siporà, filla d'en Jetró, del poble de Madian (Ex 2: 21). Ara bé, segons Nombres, Maria i Aaron reprengueren Moisés per haver-se casat amb una dona etíop (Nm 12,1). L'explicació que més endavant donarà el nostre cronista, en un incís explicatiu un xic improvisat, és que els madianites són dits, també, etíops i, per tant, la muller etíop i la madianita Siporà serien la mateixa persona:

En aprés, partiren-se d'allí e anaren-se'n [a] Aseroch e allí barallaren-se Aron e na Maria, germans de Moysés, ab Moysés per sa muller, retraent-li que havia preses dues mullers -e no preses per ço com na Saphorà era de Median, que són dits ethiops- e pres la filla del rey de Ethiòpia (f. 65r).

Aquesta identificació dels madianites amb els etíops provindria, segons la font del nostre cronista, del Paralipomen (Migne 1855: 1227 i 2Cr 14: 1-14). Abans, però, en la narració de l'Èxode, la crònica insereix la llegenda del fugaç matrimoni de Moisés amb la filla del rei de Sabà i l'estratagema fantàstica amb què Moisés va eludir aquell vincle matrimonial. Amb la incorporació d'aquesta llegenda, prenien sentit les acusacions de bigàmia envers Moisés de Maria i Aaron que conté el relat de Nombres:

REVISTA VALENCIANA DE FILOLOGIA / IV (2020) p. I37-I64 JACOB MOMPÓ NAVARRO Falsament acusades d'adulteri / I4 I 
E en aquell temps vengueren los ethíops e gastaven tot Egipte. E lo rey pharaó féu Moysés príncep de la sua cavalleria, lo qual, passat lo riu, anà per uns llochs muntanyosos plens de serpents. E portà moltes sigonyes ab si, qui·s menjaren les serpens. E ell passà de liurament e encontrà los ethíops e vencé aquells. E perseguílls tro a la ciutat de Sabba e asethjà aquella. E Tàliber, filla del rey, dels murs veu Moysés tant bell, tramés-li a dir que, si la prenia per muller, que ella li daria la ciutat. E Moysés lo y promés e aquella lliurà-li la ciutat, e ell pres-la per muller. E aquella lo amava molt, e tant que no·l perdia de vista. Entant que Moysés ac a fer dos anells, hu de oblit e altre de amor, e donà a Tàliber lo anell de oblit e aquella, tantost que.l tench, lo oblidà. E llavors, Moysés se'n tornà en Egipte (ff. 48v-49r).

Adulteri, anell i protagonista masculí són també tres dels elements que conté una altra llegenda que recull la Crònica universal de 1427, en aquest cas, durant la redacció del IV Llibre de Reis. En aquest fragment el cronista explica la manera amb què Gigues, gràcies a un anell fantàstic i a l'adulteri comés amb la reina, ascendí en l'escalafó social, de pastor a rei de Líbia:

En l'any XIII· de Menassés, regnà Gigues en lo regne de Líbia; del qual diu Túl-lius ${ }^{3}$ que, com ell fos pastor de bestiar e fes gran pluja, veu allà en una caverna de la terra e trobà un hom mort seent en un cavall de coure, en lo dit del qual trobà hun anell per lo qual era fet invicible. E ab aquest anell féu adulteri ab la regina. E aquella ajudant matà lo rey, son marit, e féu-se rey. Lo qual, elevat e inflat per lo regne, anà al déu Appol·lo e demanà si havia negú hom mortal pus rich que ell, lo qual li respòs que Ysarcadus era pus rich que ell. Aquest Ysarcadus era molt pobre, havent tansolament una somera. E aquest, vehent la pobresa tan gran de aquell altre, dix a Apol·lo com podia ésser açò com aquell fos tant pobre e ell tant rich, lo qual li respòs: "Aquell viu ab goig e sens temor e tu vius ab temor de perdre lo regne». E aquest Giges fou hoffegat ab sanch e mort (f. 110r).

3 A l'original, «Trill». El passatge es refereix a Marc Tul·li Ciceró.

REVISTA VALENCIANA DE FILOLOGIA / IV (2020) p. I37-I64 JACOB MOMPÓ NAVARRO Falsament acusades d'adulteri / I42 
Encara en aquest mateix capítol, la crònica explica la decisió de Selentus de Roma d'aplicar contra el seu fill el càstig que contra els perpetradors d'adulteri prescrivia la llei. En aquest brevíssim fragment la crònica ens descriu, almenys indirectament, el protagonista de l'acció adúltera com un personatge que gaudeix de l'estima generalitzada de la ciutat, atés que tots els ciutadans de Roma clamaven pel seu perdó. Així doncs, Selentus, per tal d'acontentar la població i, alhora, respectar la llei, decidí compartir part de la pena que hauria estat imposada al seu fill:

En aquest temps, Zelentus de Roma havia hun fill, lo qual devia perdre abduy los hulls per adulteri que havia feyt, e tota la ciutat volia perdonar. E per ço que la ley per aquell feyta no fos trencada, féu traure a son fill hun ull e a si mateix un altre (f. 110r).

El primer relat que incorpora la crònica en què un home virtuós defensa una dona falsament acusada d'adulteri prové, encara, del material bíblic. Es tracta de la història del profeta Daniel i Susanna, que havia estat acusada d'adulteri i conduïda a l'esplanada on s'havia d'aplicar la sentència, això és, la mort per apedregament:

En aquest temps, Daniel levà Susanna de la infàmia de l'adulteri que li havien imposat. E portant-la al loch hon la havien a pedregar, Daniel féu aturar tota la gent e apartà los testimonis que la havien acusada, cascú a sa part, e dix a l'hu en quin loch havien fet lo mal. E aquell dix que davall hun pruner, e l'altre dix que davall hun pomer. E lavors Daniel dix que fossen turmentats, los quals atorgaren que falsament la havien acusada; e lavors aquella fou delliurada e aquells foren apedregats (f. 115r).

Aquesta història presenta paral-lelismes amb el relat de la dona adúltera de Joan (8, 1-11), que la Crònica universal de 1427 explica d'aquesta manera:

Aprés, en lo dilluns següent, tornà Jesucrist en Jerusalem e preÿcà en lo temple, segons diu sent Johan, Johanis, ·VIII· capitulo. Quant hac preÿ-

REVISTA VALENCIANA DE FILOLOGIA / IV (2020) p. I37-I 64 JACOB MOMPÓ NAVARRO Falsament acusades d'adulteri / I 43 
cat, los sacerdots fariseus e scrivans de la ley presentaren-li una fembra qui era estada trobada en adulteri dient que la jutjàs assí, que si la condempnàs a mort, que los parents de aquella lo matassen com fos de bons amichs; e si la absolvia, que·l prenguessen per trencador de la ley e que.l matassen. E Jesucrist, veent la lur mala intenció, dix-los: "Aquell de vosaltres qui és sens peccat tire-li la primera pedra». E baxà's e scriví en terra en lo dit. E cascuns de aquells, vehent los lurs peccats, aquí tots se n'anaren que no n'i romàs negú. E lavors dix Jesucrist a la fembra: «Hon són los qui t'acusen?» La qual respòs: «Senyor, no n’i ha nengú». Dix-li Jesucrist: "Yo no•t condapnaré, ves-te'n; d'aquí havant no vulles peccar». E fet açò, tornà-se'n en Bethània (ff. 143r-143v).

No té, en canvi, tantes implicacions heroiques el paper de defensor de la dona adúltera que a la crònica protagonitza Hipòcrates. Segons el cronista, el metge grec dictà que el naixement d'un nadó negre al si d'un matrimoni de blancs no s'havia produït mitjançant adulteri, sinó gràcies a una explicació no tan carnal, i una mica més fabulosa:

Hon en los libres de Ypocràs se lig que una dona havia parit hun fill molt negre, e lo marit dix-li que no era son fill e acusà-la de adulteri davant lo jutge. E Ypocràs, sabent açò, anà a casa de la dona e entrà en la cambra hon tenia lo lit. E veu als peus del lit, pintat en la paret, hun ethíop. E lavors Ypocràs jutjà que per la pintura que era en la paret se era esdevengut, e açò per ymaginació en lo concebiment (f. 121v).

El següent relat en què la Crònica universal de 1427 tracta el tema de l'adulteri és durant la narració de la infància i casament de la Verge Maria. En aquest sentit, per al nostre cronista, el matrimoni de la Verge amb Josep va ser concebut per Déu per tres motius. D’una banda, perquè Josep tinguera cura de Maria i del fill de Déu; així mateix, per tal d'amagar el naixement de Déu al diable, tot fent-li creure que el fill era natural de Josep; però, sobretot, per preservar la fama de la Verge i no fer creure els seus contemporanis que Maria havia engendrat Jesús fruit d'una relació adúltera:

REVISTA VALENCIANA DE FILOLOGIA / IV (2020) p. I37-I64 JACOB MOMPÓ NAVARRO Falsament acusades d'adulteri / I 44 
E quant aquella agué.XIIII anys, lo sacerdot li dix que la tornaria a casa de son pare per ço que prengués marit, la qual li respòs que no volia marit com hagués fet vot de virginitat. E lavors lo sacerdot consultà nostre senyor Déu, lo qual li tramés a dir per l'àngel que ajustàs tots los hòmens del linatge de Daviu, qui eren del trip de Judà, que no havien mullers e que passasen davant l'altar ab sengles vergues seques en les mans; e aquell del qual la verga floriria, que aquell fos spós e marit de la dita Verge. E tramés a dir per l'àngel a la dita Verge que consentís al matrimoni, car la sua virginitat seria salva e conservada. E passants aquells davant l'altar, la verga de Josep florí e aquell fou espós <espós> e marit de la dita Verge Maria per social habitació. E volgué Déus que la sua mare fos maridada per ço que fos acompanyada e servida per aquell e, axí metex, per guardar e conservar la fama de la dita Verge, car alguns agueren dit per havant, com ella consebé lo fill de Déu, que l'havia concebut en adulteri si no hagués marit; axí matex, per ço que la incarnació del fill de Déu fos cuberta e celada al diable, cuydant que era de Josep (ff. 134v-135r).

\section{Falsament acusades d'adulteri}

\subsection{La llegenda de la virtuosa Lucrècia}

La llegenda de la virtuosa Lucrècia prové de la tradició recollida per Titus Livi a les seues Dècades. A grans trets, Livi situa l'inici de la llegenda durant el setge a la ciutat d'Ardea, al si d'una disputa sorgida entre Sext Tarquini, fill del rei Tarquini el Superb, i Col·latí Tarquini, marit de Lucrècia, sobre quina de llurs mullers era més virtuosa. Ambdós disputants decidiren cavalcar fins a Roma per comprovar-ho. Una vegada allà van ser testimonis de com, mentre la resta de dones de la ciutat passava el temps entre festes i banquets, Lucrècia aprofitava per teixir peces de roba, fet que demostrava, a ulls dels dos homes, la virtuositat de la muller de Col·latí. Aquest decidí convidar els seus companys de disputa a un sopar. Durant l'àpat, Sext Tarquini va sentir la necessitat de posseir Lucrècia. Poc després, aprofitant que Col·latí estava absent, va anar a casa de Lucrècia, on va ser rebut amb honors, com pertanyia al fill d'un rei. A

REVISTA VALENCIANA DE FILOLOGIA / IV (2020) p. I37-I64 JACOB MOMPÓ NAVARRO Falsament acusades d'adulteri / I45 
la nit, Sext va violar Lucrècia tot amenaçant-la, si no accedia als seus desitjos carnals, amb una falsa acusació d'adulteri, això és, que la mataria a ella i a un esclau seu perquè tothom pensara que havien sigut sorpresos en adulteri. Després d'explicar-li els fets a son marit, Lucrècia es va suïcidar amb un punyal. Com a resultat d'aquest fet, el poble de Roma es rebel-là contra la família reial, que es va veure obligada a marxar exiliada. Sext Tarquini, per la seua part, fugí a la ciutat de Gabii, on morí assassinat pels seus habitants. Després d'aquests fets, els romans feren cònsol Luci Juni Brut, nebot de Tarquini el Superb (Ferrer Santanach, 2010: 417-433).

La Crònica universal de 1427 ens presenta una versió breu de la llegenda, però amb alguns trets que la diferencien de la de Livi. En aquest sentit, malgrat que la font de la secció on s'encabeix aquesta llegenda explica succintament el setge d'Ardea, des d'on arranca la llegenda de Titus Livi (Beauvais, 1591: 32v), la crònica no fa esment d'aquest episodi, ni de la disputa entre Col-latí i Tarquini, i inicia la seua versió de la llegenda situant-nos Sext Tarquini enamorat de Lucrècia. Aquest, amb l'excusa que venia de caçar, i aprofitant l'absència del marit, accedí al castell de la dama. Després de sopar, Tarquini accedí per una finestra a l'habitació de Lucrècia, on la va violar. El desenvolupament dels esdeveniments segueix amb poques variacions fins al final, on segons la crònica, la família reial al complet morí en l'incendi del seu palau provocat pels ànims de revenja del poble de Roma i no exiliada, com en la versió de Titus Livi, o com en la brevíssima referència que n'havia fet la principal font d'aquesta secció de la crònica: «Cumque oppugnaret Ardeam causa Tarquinii minoriis filii sui, qui Lucretiam corruperat, regno expulsus est» (Beauvais, 1591: 32v).

D'altra banda, segons Ferrer Santanach, el fragment que narra aquesta llegenda a la Crònica universal de 1427 beuria de la Crònica universal de 1425, tot i que aquella abreujaria molt aquesta (Ferrer Santanach, 2010: 69). Això no obstant, justament el caràcter breu de la llegenda en la Crònica universal de 1427 dificulta la detecció de la font directa. A més, els elements significatius del relat de la Crònica universal de 1427 que divergeixen del text de Titus Livi, com ara la mort de tota la família reial romana a l'incendi del palau, no són presents tampoc en la de 1425. Aquesta particularitat, tot i que no ens duu a

REVISTA VALENCIANA DE FILOLOGIA / IV (2020) p. I37-I64 JACOB MOMPÓ NAVARRO Falsament acusades d'adulteri / I 46 
descartar plenament la Crònica universal de $1425^{4}$ com a material que hauria resumit el compilador de la de 1427, tampoc no ens permet d'identificar-la de manera infal-lible com a font directa del passatge:

En lo X-any de Dari, los reys de Roma deffalliren, mort e foragitat Tarquinus Superbus, los quals regnaren ·CCCL-anys. Car, esdevench-se que Tarquinus lo Menor, fill seu, se enamorà de una gran dona de Roma, que havia nom Lucrècia. E aquella stant en un castell seu, Tarquinus, sabent que son marit no y era, per scusa que venia de caçar arribà al castell ja prop del vespre. E Lucrècia acullí-lo bé, axí com a fill de son senyor, e donà-li a sopar. Aquest se pres bé sment de la cambra hon aquella dormia. E com fonch ora de dormir, féu-lo entrar en sa cambra e ella anàsse'n a dormir en la sua cambra. E quant vench en la nit, aquell se levà e, per una finestra que havia en la cambra de aquella, ell li entrà dins e dix: «Si tu no consents a ma voluntat, yo degollaré lo teu esclau e metré'l-te al costat e degollar t'e a tu. E diran que, per ço com te he trobada que feyes mal ab lo teu sclau, te he morta». La qual, veent-se en tan gran perill e que no fos diffamada a tort, consentí a ça voluntat. E quant vench per lo matí que aquell se levà per anar-se'n, Lucrècia se retench lo coltell de aquell. E de continent que.s fonch levada, tramés a dir a son pare e a son marit que vinguessen de continent, los quals tantost vengueren. E aquella los comptà lo cars que li era esdevengut, e, per ésser diffamada a tort ni ells romanguessen injuriats ni ab vergonya, ella havia consentit. E açò.ls deya perquè sabessen la veritat, mas no per scapar a mort. E perquè fos exemple a altres, mes-se lo coltell de Tranquinus que tenia en la mà per lo ventre e morí de continent. E com aquells veren la cosa tant desastrada, prengueren lo cors de aquella e vengueren-se'n a Roma e concitaren e comogueren tot lo poble. E anaren al palau de Tranquinus e cremaren a Tranquinus e tots sos fills dins aquell. E fet açò, feren conjuració de no haver rey de aquí havant en Roma. E feren cònsols, e·n aprés tribuns, e la final, feren cònsols per regir la cosa pública. E lo primer cònsol fou Bruto, nebot de Tarquinus. E regiren-se axí per CCCCLXIIII anys, entrò

4 La versió de la llegenda en la Crònica universal de 1425 a Ferrer Santanach (2010: 498-502 i 2013).

REVISTA VALENCIANA DE FILOLOGIA / IV (2020) p. I37-I64 JACOB MOMPÓ NAVARRO Falsament acusades d'adulteri / I 47 
a Juli Cèsar, que sols e singular, pres lo imperi e fou lo primer emperador de Roma (ff. 119v-120r).

\subsection{La llegenda de l'emperadriu d'Alemanya}

Poc abans de la inclusió de la llegenda de l'emperadriu d'Alemanya, el cronista de 1427 enceta la secció dedicada a la història catalanoaragonesa. ${ }^{5}$ Fins aquell moment, la crònica s'havia centrat a narrar el decurs de la història des d'una òptica universal. A partir de l'any 890, moment en què els diferents esdeveniments van propiciar l'alliberament del vincle vassallàtic amb la monarquia franca, la crònica comença a barrejar la cosa universal amb les gestes protagonitzades per personatges vinculats a la Corona d'Aragó. En aquest cas la crònica adapta a la seua redacció, tot i que succintament, un dels mites fundacionals de Catalunya que més fortuna van tenir, sobretot, a partir del segle Xv. En aquest sentit, si bé és cert que gran part de la historiografia catalana medieval considerava el comte franc Guifré el Pilós com l'heroi fundacional, aquesta llegenda, tot i que amb connotacions antifranques, no deixava de reconéixer l'ascendència franca de Catalunya. I més o menys en aquests termes es mantingué al llarg de l'edat mitjana (Ferrando 1996: 209). Ara bé, a principis del xv diverses cròniques van donar una nova versió dels orígens de Catalunya segons les quals l'heroi fundador hauria estat un cavaller d'ascendència germànica, Otger Cataló, qui, juntament amb nou barons va aconseguir alliberar Catalunya de mans sarraïnes. ${ }^{6}$ L'autor de la llegenda que incorpora en aquest punt el nostre compilador pren elements de la llegenda d'Otger Cataló, malgrat que en aquest cas el nom de l'heroi és Ramon Berenguer i els nou barons que l'acompanyen augmenten a dotze. Segons la crònica, davant la negativa del monarca

5 A partir de l'any 980, el compilador va alternant diferents relats basats en la història catalanoaragonesa amb les històries extretes del Chronicon pontificum et imperatores, de Martí de Troppau. No és fins que acaba d'extractar el Chronicon, coincidint amb el regnat de Pere el Gran, que el compilador se centra definitivament a narrar la història dels monarques de la Corona d'Aragó, bandejant l'òptica universal que havia caracteritzat la crònica.

6 És imprescindible l'estudi de la llegenda que feu Coll i Alentorn (1949). Igualment interessant és la visió més recent de Cingolani (2008: 21-39).

REVISTA VALENCIANA DE FILOLOGIA / IV (2020) p. I37-I 64

JACOB MOMPÓ NAVARRO

Falsament acusades d'adulteri / I48 
franc a conquerir Catalunya als sarraïns, l'egregi baró en Ramon Berenguer i les seues tropes alemanyes assetjaren i conqueriren Barcelona l'any 980 i els territoris catalans foren subjugats a l'Imperi germànic. D'aquesta manera, la crònica explicaria la desvinculació de Catalunya de la monarquia franca:

En aquest temps de Othó, lo molt egr[eg]i baró en Ramon Berenguer ab altres barons de Alamanya vingueren a Roma al papa dient-li que Cathalunya era conquesta per serraïns, e possehida per aquells la major part; e que la conquesta era del rei de Ffrança, per què.l supplicaven que ell trametés a requerir lo rei de Ffrança que la conquistàs o renunciàs a la conquesta. Lo qual, de continent, tramés sos misatgers al rei de Ffrança, lo qual respòs que no podria a present e que li plahia renunciar. E féu-ho de continent. E tornats los misatgés ab la resposta, lo dit noble baró en Ramon Berenguer se n'anà en Alamanya e vench ab gran gent en gran noblea; e fou en lo·XVIII any de l'emperador Othó. E assetjà Barchinona, qui era de serraïns del temps dels gots ençà que·s perdé Spanya e pres aquella en l'any de nostre senyor DCCCCLXXX-anys. E fou fet comte de Barçalona e féu en Cathalunya $\cdot \mathrm{XII}$ comdats e XII-vescondats e.XII varvesors, XII-cases de nobles hòmens e mil CC.cases de cavallers. E tots aquest foren subjugats a l'Imperi, ço és, a Othó. Aprés foren franchs de l'Imperi (ff. $175 \mathrm{r}-175 \mathrm{v}$ ).

Ara només li restaria al nostre cronista explicar l'alliberament del jou germànic. I en aquest punt és on entra en joc la llegenda de l'emperadriu d'Alemanya. Així doncs, unes poques línies després del passatge suara transcrit, l'autor insereix a la seua narració la llegenda de l'emperadriu d'Alemanya, la qual explica el motiu pel qual el comte aconseguiria l'alliberament del jou germànic i, de retruc, la donació del comtat de Provença. L'autor no especifica el nom del comte protagonista de la llegenda, però el context fa entendre que es tracta del mateix Ramon Berenguer, a qui atribuïa poc abans la conquesta de Barcelona. El compilador emmarca la llegenda en temps de l'emperador Enric II el Sant, per bé que s'hi refereix com a Enric «lo Primer» (f. 176r). Això és així perquè el Chronicon de Martí de Troppau, que és la font principal d'aquesta

REVISTA VALENCIANA DE FILOLOGIA / IV (2020) p. I37-I64 JACOB MOMPÓ NAVARRO Falsament acusades d'adulteri / I 49 
secció de la crònica, explicita que Enric I no va ser emperador «Unde nec ipse inter imperatores conputatur, quia non regnavit in Ytalia nec fuit per papam coronatus» (Weiland 1872: 464). És possible que seguir la llista d'emperadors i papes de Martí de Troppau permeta al compilador d'enllaçar una llegenda amb l'altra. En aquest sentit, el Chronicon remarca la santedat de l'emperadriu i, potser, el cronista identifique sense fer-ho explícitament l'emperadriu de la llegenda amb l'esposa d'Enric II, santa Cunegunda. Segons Martí de Troppau: «Huius Henrici imperatoris uxor fuit sancta Cunegundis et ambo virgines permanserunt» (Weiland 1872: 464).

La llegenda de l'emperadriu, de manera molt més extensa, ja la inclou Bernat Desclot en la seua crònica, primer testimoni escrit de la llegenda (Alcoberro 2003: 145; Saladrigues i Torné 2007: 1). Tanmateix, tant el caràcter breu de la narració de la Crònica universal de 1427, com la inclusió d'altres elements que no són presents a l'obra de Desclot, impedeix identificar la crònica d'aquest darrer com a font directa del nostre cronista, per bé que la Crònica de Desclot serà una de les fonts del nostre compilador a partir del regnat de Pere el Gran. D'altra banda, la justa del comte de Barcelona en defensa de l'honor de l'emperadriu d'Alemanya falsament acusada d'adulteri ha estat un tema recurrent en la historiografia catalana, sovint utilitzat en nombrosos relats que tracten de justificar el domini legítim del comtat de Provença, com ara les versions de la llegenda del Flos Mundi, el Libre de les nobleses dels reys, de Joan Francesc; el Recort, de Gabriel Turell; les Chròniques de Espanya, de Pere Miquel Carbone11; el Sumari d'Espanya, de Berenguer de Puigpardines; o la Crónica general de España, de Pere Antoni Beuter, entre d'altres, a banda de l'esmentada Crònica de Bernat Desclot (Cortadellas 2001: 127).

Antoni Ferrando (1996) va establir quatre tradicions que han transmés la llegenda, sensiblement diferents entre si: la família catalana, la francoanglesa, la centreeuropea i la provençal. Sembla que l'origen comú de totes aquestes famílies de la llegenda és la històrica aliança de l'emperadriu Judit, segona muller de Lluís I el Pietós, amb Bernat de Septimània, comte de Barcelona, Tolosa i Narbona. Amb aquesta aliança s'afavoria políticament el fill de l'emperadriu, Carles el Calb, que va obtenir el control de la part occidental de l'Imperi que

REVISTA VALENCIANA DE FILOLOGIA / IV (2020) p. I37-I64 JACOB MOMPÓ NAVARRO Falsament acusades d'adulteri / I 50 
havia forjat el seu avi Carlemany. L'emperadriu va ser acusada d'adulteri amb el comte Bernat, tot i que ambdós van ser, finalment, absolts. Aquests esdeveniments van ser difosos per tot Europa gràcies a Pascasi Radbert, el qual redactà un pamflet que contenia, a grans trets, aquest relat històric. Posteriorment, es va redactar un romanç en occità titulat, probablement, Lo comte de Tolosa. Aquest romanç degué servir de base per a la redacció en català de l'anònim Romanç del comte de Barcelona e rey d'Aragó, actualment perdut (Aguilar 2005: 64-65). La transformació d'aquest relat en llegenda historiogràfica tenia una intencionalitat política; en el cas de les versions de la família catalana, legitimar el comtat de Provença dins l'òrbita dels comtats catalans.

La versió de la Crònica universal de 1427 presenta algunes peculiaritats respecte al primer testimoni escrit de la llegenda. En primer lloc, per a la Crònica de Desclot, l'emperadriu objecte de l'acusació és la filla del rei de Bohèmia (Desclot 1885: 44); igualment, així apareix identificada al Sumari d'Espanya, de Berenguer de Puigpardines, que depén de l'obra de Desclot (Iborra 2000: 52). La Crònica universal de 1427 no explicita el nom de l'emperadriu, però hem vist que el context de la crònica fa identificar-la amb santa Cunegunda, l'esposa de l'emperador Enric II. A més, la versió de Desclot identifica Provença com el lloc de procedència de Bertran de Rocabruna, el company de viatge del comte que va fugir acovardit abans del combat. En canvi, per al cronista de 1427 Rocabruna és napolità. La nacionalitat napolitana del covard Rocabruna a la crònica no sembla casual, sinó que, més aviat, respondria a les aspiracions d'Alfons el Magnànim sobre el regne de Nàpols, que devien seguir vives en el moment de redacció de la crònica (Ferrando 1996: 211).

D'altra banda, el comte de Barcelona de Desclot, en arribar a Alemanya, parla primerament amb l'emperador, a qui demana permís per entrevistar-se amb l'emperadriu. Contràriament, a la Crònica Universal de 1427 el comte acudeix abans a l'emperadriu, tal com fa, també, el protagonista d'aquest passatge a les Cròniques d'Espanya, de Pere Miquel Carbonell. En aquest mateix context, Carbonell explica l'ardit del comte per mantenir-se en l'anonimat, això és, visitar l'emperadriu camuflat amb hàbit religiós «de pare confessor» (Carbonell, 1546: 38r). A la crònica, el comte s'oculta sota un hàbit «de frare

REVISTA VALENCIANA DE FILOLOGIA / IV (2020) p. I37-I64 JACOB MOMPÓ NAVARRO Falsament acusades d'adulteri / I 5 I 
preÿcador» (f. 176v). En canvi, al text poètic llatí de l'Exordium Populeti, l'hàbit amb què s'oculta el comte és de l'Orde del Cister. Segons els seus editors: «la mudança [...] s'explica fàcilment pel designi central del poema, que era lligar la prestigiosa llegenda del Bon Comte a la fundació d'un gran monestir de l'Orde de Cister» (Saladrigues i Torné, 2007: 12). No sabem si la Crònica universal de 1427 va ser redactada dins l'òrbita de l'orde dels dominics; excepte aquesta particularitat de l'hàbit del comte, les referències a ordes religiosos al llarg de la crònica són anecdòtiques, puntuals i provenen directament i literal de les seues fonts. Potser la font d'on el compilador va extractar la llegenda sí que es va confegir dins l'àmbit de frares predicadors, no ho sabem.

Una altra diferència important entre la Crònica universal de 1427 i la de Desclot és el relat del viatge de l'emperadriu d'Alemanya a Barcelona. El text de Desclot explica que l'emperadriu va anar a Barcelona per demanar al comte que l'acompanyara a Alemanya, però no esmenta les festes que relata la nostra crònica per celebrar la vinguda de l'emperadriu. Segons la tradició popular, les viandes servides durant aquelles festes inspiraren la dita popular «taula de Barcelona és taula bona» (Aguilar, 2005: 70). Així doncs, per bé que el nostre cronista coneix l'obra de Desclot, com així es palesa més endavant, la seua versió de la llegenda de l'emperadriu sembla més pròxima als materials que posteriorment degué fer servir Carbonell per a les seues Cròniques d'Espanya:

Enrich lo Primer fo emperador XIII-anys. Aquest era duch de Baviera e fou lo primer emperador fet per elecció dels alamanys. En aquest temps la luna se convertí en sanch. Aquest hagué moltes batalles en Germània, en Boèmia e en Ytàlia e hac fi maravellosament e bé. Esdevench-se en lo primer any del seu imperi que la inperadriu, ça muller, fou acusada de adulteri per dos cavallers molt forts e grans hòmens, la qual dix que no havia culpa. E l'emperador li féu assignació que dins hun any hagués trobat cavaller que la deffenés, si no, que passat lo terme la cremaria; la qual tramés misatgers per totes les parts del món a cercar qui la volgués defendre, e no trobà nengú. E venint hu dels misatgers al comte de Barchinona, e dix-li com dos cavallers falsament havien acusada la emperadriu de Alamanya, e que l'emperador li havia donat terme de hun any que

REVISTA VALENCIANA DE FILOLOGIA / IV (2020) p. I37-I64 JACOB MOMPÓ NAVARRO Falsament acusades d'adulteri / I 52 
hagués trobat cavaller qui la deffenés del crim ha aquella imposat; al qual ja no havia a passar sinó hun més. Per ço pregava ha ell, axí com aquell qui havia fama del millor cavaller del món, que la volgués defendre. E lo comte li respòs que ell era occupat de altres affers e que al present no $\mathrm{u}$ podia fer e que se'n tornàs, que Déu li hajudaria.

E tantost que.l misatger se'n fou partit, lo comte pres en Bertran de Rochabruna, cavaller napoletà molt fort, en ça companyia e mes-se al camí per anar en Alamanya secretament ab hàbit desfraçat. E com fonch en Alamanya, vench a la emperadriu vestit ab hàbit de frare preÿcador e dix-li que ell era vengut per combatre's per ella, axí que li digués veritat si havia culpa; la qual respòs que no havia culpa en càrrech de la sua ànima. E lavors lo comte li dix que estigués ab bon cor. E aquella li demanà qui era e, rebut sagrament d'aquella que no·l descobriria a negú tro fossen passats tres dies del camp, dix-li que ell era lo comte de Barçalona, de la qual cosa aquella fou sobiranament alegra. E dix a l'emperador com ella havia trobat cavaller qui la deffendria e ja no havia tro al terme sinó quatre dies. E quant vench lo dia del camp, lo comte se levà per lo matí e demanà $a \cdot n$ Bertran de Roquabruna, lo qual se fonch anat que no.l trobaren. E lavors lo comte se armà e anà-sse'n al camp hon trobà ja lo emperador e la emperadriu ab sos cadafals, e la lenya apparellada e los dos cavallers al camp. E lo comte dix a l'emperador la falta que son companyó li havia feta, e axí que ell se combatria abduy los cavallers, hu aprés altre; e lo emperador dix que rahó era. E lavors lo pus fort cavaller d'aquells fou arreat e vench devers lo comte. E lo comte lo ferí de la lança per los pits, que la-y travesçà per lo cors, e abeté'l mort a terra. E com fo al cap del cors esperà l'altre cavaller, lo qual li dix que no·s volia combatre e confessà la sua malvestat: que per enveja li havien abdosos imposat aquell crim. E lavors lo comte lo tramés a l'emperador e lo emperador lo tramés a la emperadriu. E aquella, per reverència de Déu e per la gràcia que li havia Déu feta, perdonà-li ab que jamés no li fos davant.

E fet açò, l'emperador e l'emperadriu, per sobres de goig que hagueren, vengueren-se'n a lur posada e estigueren ab gran solaç, que no·ls membrà del cavaller que havia vençut lo camp. E com se volgueren dinar, lo empe-

REVISTA VALENCIANA DE FILOLOGIA / IV (2020) p. I37-I64 JACOB MOMPÓ NAVARRO Falsament acusades d'adulteri / I 53 
rador demanà lo cavaller e digueren-li que, de continent que hac vençut lo camp, se n'anà cuytadament, de la qual cosa lo emperador fou molt despagat, e tramés-li detràs e no•l trobaren. E dix a la emperadriu: «Qui era lo cavaller?». La qual li dix que no lo y podia dir tro que aguessen passats tres dies. E com foren passats, aquella li dix que lo cavaller que la havia deffessa era lo comte de Barchinona, de qual lo emperador hac gran plaer. E lavors dix a la emperadriu que anàs en Cathalunya e portàs ab si lo compte de Barchinona, e que no tornàs menys d'aquell. E de continent, aquella se mes en lo camí molt honradament acompanyada.

E com lo comte ho sabé, vench-se'n a Perpinyà e aquí la rebé molt altament e vengueren-sse'n en Barçalona. E una letgua ço de Barchinona fins a Muncada lo comte féu entalamar lo camí dalt e debax a cada costat del camí de molt richs e bells draps. E de loch en loch, riques tendes per aleviar la gent, les taules parades que la una tocava a l'altra de Barchinona fins a Muncada, en les quals havia de precioses viandes e de singulars vins, e habundantment de moltes maneres de viandes per festejar l'emperadriu en son degut loch e les altres nobles companyes que ab si portava. E aprés dinar, entraren en la ciutat de Barchinona, hon fo rebuda molt altament e feren-li molt gran festa. E acabada la festa, ella li dix la causa per què venia. E aprés alguns dies, ell se mes al camí ab la emperadriu e anaren en Alamanya. E com foren aquí, lo emperador li féu molt gran festa e li féu moltes gràcies de la honor que li havia feta en deffendre l'emperadriu. E lavors donà-li lo comdat de Prohença e remés Cathalunya del jou de l'Imperi, e donà'ls libertats e franqueses e molts privilegis. E aprés de moltes grans festes, tornà-sse'n en Cathalunya (ff. 176r-177v).

\subsection{La reina calumniada}

El cronista inicia la història de la part aragonesa de la corona situant la resistència contra la invasió sarraïna a les muntanyes de Jaca. En aquest punt, aprofita l'avinentesa per afegir a la crònica un altre relat que gira entorn d'una falsa acusació d'adulteri, la llegenda de la reina calumniada. Però la versió de la Crònica universal de 1427, malgrat que és breu, presenta particularitats interessants respecte a la versió més divulgada de la llegenda. L'acusació d'adulteri, en aquest cas,

REVISTA VALENCIANA DE FILOLOGIA / IV (2020) p. I37-I64

JACOB MOMPÓ NAVARRO

Falsament acusades d'adulteri / I 54 
va dirigida contra Sança, segons la crònica, senyora de Montaragó i esposa del rei de Castella, acusada d'adulteri per dos dels seus fills. Segons el relat del compilador anònim, farcit d'inexactituds històriques, un fill bastard del rei de Castella, el futur rei Sanç Avarca, s'encarregà de defensar l'honor de la reina calumniada. El resultat de la justa és semblant al del combat per l'honor de l'emperadriu d'Alemanya; en aquest cas, tots dos acusadors es retracten $\mathrm{i}$ admeten que havien acusat la dama falsament per enveja. En agraïment per la defensa de l'honor de la reina, Sanç Avarca va ser nomenat rei d'Aragó, per bé que no va poder perpetuar el seu llinatge atés que va morir sense descendència. La conseqüència d'aquesta mort sense hereus fou que els cavallers aragonesos elegiren rei Ramir I d'Aragó.

La llegenda de la reina calumniada és un tema recurrent, com veurem, en diversos escrits historiogràfics, tot i que no sempre respon a la mateixa finalitat, que s'entreveu a la brevíssima versió de la Crònica universal de 1427. El propòsit, a grans trets, de la llegenda de la reina calumniada era explicar, d'una banda, el repartiment del territori que feu Sanç III el Major i, de l'altra, l'ascens al tron d'Aragó del bastard del rei, Ramir I. Ara bé, la Crònica universal de 1427 conté diverses confusions històriques que propicien un desenllaç de la llegenda que, a parer nostre, tenen una intencionalitat clara. En primer lloc, per a la crònica, la reina calumniada és Sança, senyora de Montaragó i esposa del rei de Castella. En canvi, la Crònica Nagerensis, primer text en llatí que ens ha transmés la llegenda, explica que Garcia, primogènit de Sanç III Garcés el Gran (c. 996-1035), s'enfadà amb sa mare, Múnia, perquè no va permetre que l'infant cavalcara un cavall del rei. Garcia, amb ànims de revenja, acusà falsament la seua pròpia mare d'haver comés adulteri amb un cavaller. Llavors, Ramir, bastard del rei, defensà l'honor de la reina calumniada. Com a recompensa, Ramir va rebre els territoris d'Aragó i, amb el temps, es va convertir en el primer monarca aragonés.7

Diverses cròniques aragoneses esmenten una filla del rei de Navarra casada amb un rei de Castella, com ara la crònica de Guadalberto Fabricio Vagad o la de Lucio Marineo Siculo, que situen Sança com a filla de Sanç II Garcés,

7 Han aprofundit en la llegenda així com en les diferents justificacions Ward (2010), Pattison (1982; 1997), Deyermond (1995) Ramos (1981) i, encara, Menéndez Pidal (1923).

REVISTA VALENCIANA DE FILOLOGIA / IV (2020) p. I37-I64 JACOB MOMPÓ NAVARRO Falsament acusades d'adulteri / I 55 
Avarca (c. 936-994) i esposa del rei Ramir de Castella (Vagad 1499: 19v; Marineo Siculo 1524: 7r). Però aquesta Sança correspondria, cronològicament, a una generació anterior a la dels personatges que, tradicionalment, han protagonitzat aquest episodi llegendari. D'altra banda, Sanç II era el pare de Sança si és que es tracta del mateix personatge i no el fill bastard del rei o comte, segons cronistes de Castella, que la crònica no especifica, però si fem cas de Vagad i Marineo Siculo, es tractaria de Ramir de Castella. Avarca tampoc no va ser mai rei d'Aragó, sinó de Nájera-Pamplona; ni, per tant, el va succeir Ramir I. Entre Avarca i Ramir, doncs, se salta els reis de Pamplona i comtes d'Aragó Garcia Sanxes II, el Tremolós, i Sanç III Garcés, el Gran. Aquest, segons les cròniques, es va casar amb la filla del comte de Castella, amb qui va tenir fills. Però va engendrar el futut rei Ramir I d'Aragó amb la senyora na Sança d'Aibar, també coneguda, segons cronistes, com Baia o Elvira. ${ }^{8}$

D'altres obres, com l'esmentada crònica de Vagad, defensen la legitimitat de Ramir I argumentant que, en realitat, Sanç III s'hauria casat en primer lloc amb na Baia d'Aibar (Vagad, 1499: 20v). Aquest cronista, per a demostrar la legitimitat de Ramir, cita la «corónica más cierta, más antigua y verdadera de Sant Victorián", que, segons el cronista aragonés, "no se acontenta de provar solamente de palabra que fue legítimo [...] mas aun da fe de ello por escriptura auténtica» (Vagad, 1499: 20v). A més, critica l'actitud de Roderic Ximénez de Rada perquè aquest, a Ramir, «nunca le llamava sino fijo de otra madre» (Vagad, 1499: 21r). ${ }^{9}$

Malgrat tot, la figura del bastard reial devia planar sobre els materials historiogràfics que consultava el nostre cronista. Amb tot, la solució del compilador de la nostra crònica va ser atribuir-li l'etiqueta de fill il-legítim a Sanç

8 En aquests termes ho expliquen, a tall d'exemple, la Crònica de Sant Joan de la Penya (Ximénez de Embún, 1876: 37-44) i la crònica continguda al manuscrit BNP Ms. Esp. 13 (f. 78r-79v), totes dues dependents del De rebus Hispaniae, de l'arquebisbe Roderic Ximénez de Rada.

9 Lucio Marineo Siculo també considera Ramir fill legítim del rei, nascut durant el seu suposat primer matrimoni, en aquest cas, amb: «Doña Elvira, muger muy noble de linage y señora del castillo de Aivar». Després de la defunció d'aquesta, el monarca es va casar amb «Mayor, hija del conde de Castilla» (Marineo Siculo, 1524: 7v).

REVISTA VALENCIANA DE FILOLOGIA / IV (2020) p. I37-I 64

JACOB MOMPÓ NAVARRO

Falsament acusades d'adulteri / I 56 
Avarca. Ara bé, com a contrapartida, hagué de llevar-li a Ramir l'èpic combat per conservar la fama de la reina així com l'honor d'ésser considerat el primer rei d'Aragó. El relat que conserva la nostra crònica, doncs, conjuga la presència d'un bastard amb la legitimitat del rei Ramir I d'Aragó, el qual va ser elegit rei a la mort de Sanç Avarca, ${ }^{10}$ malgrat que, com hem explicat, sacrifique l'heroïcitat del futur Ramir I, a canvi de mantenir intacta la seua legitimitat obviant la circumstància d'haver nascut fora del matrimoni regi:

Los cristians qui-s salvaren en les muntanyes de Jaqua quant los serraïns conqueriren Spanya dels gots feren guerra contra-ls sarraïns, e guanyaren-los algunes viles e castells; e fahien príncep adés hu, adés altre. En tant que la filla del darrer príncep, dona Sancha, senyora de Montaragó, pres per marit en aquell temps lo rei de Castella, e portà-li en exovar Montaragó e totes les muntanyes de Jaqua; del qual hac dos fills.

Esdevench-se per havant que la reyna havia gran privadea e amistat honestament ab hun cavaller, e los fills hagueren-ne gran sospita per enveja del cavaller e acusaren-la davant lo rey. E ladonchs, lo rey dix ad aquella que trobàs cavaller que la deffenés, e asignà-li jornada; la qual se escusà que no havia culpa. E lo rey havia hun fill bastart que havia nom Sancho Avarcha, lo qual, vehent que l'ora de la jornada no hi venia degú per deffendre aquella, vench armat al camp dient al rey que ell la deffendria hi combatria per aquella; lo qual era valent cavaller e molt gosat. E los fills vengueren davant lo rey e la reyna dient que ells falsament la havien acusada e per enveja del cavaller, e axí que no's volien combatre; e lavors lo rey la hac per absolta. E la dita reyna pregà al rey que li plagués que

10 De la confusió entre ambdós personatges, Sanç Avarca i Ramir I d’Aragó, que presenta la nostra crònica en parla Sophie Hirel-Wouts al seu estudi sobre la institució del justícia d'Aragó (Hirel-Wouts 2006: 284-285). D'altra banda, les confusions entre personatges d'aquesta nissaga han estat freqüents al llarg de la historiografia. La Crònica legionense, o Silense, en aquest mateix passatge confon Sanç III amb el seu avi, Sanç II (Duran Gudiol, 1978: 20). Per la seua part, la Crònica i dietari del capellà d'Alfons el Magnànim se salta els regnats de Sanç II, Avarca, i del seu fill, Garcia Sanxes, el Tremolós. L'anotador del manuscrit, a més, confon Sanç III amb Sanç Avarca, tal com explica l'editor del text (Rodrigo Lizondo, 2011: 98).

REVISTA VALENCIANA DE FILOLOGIA / IV (2020) p. I37-I64

JACOB MOMPÓ NAVARRO

Falsament acusades d'adulteri / I 57 
ella pogués donar Muntaragó e totes les muntanyes al dit don Sancho Avarcha, e que fos rey d'Aragó. E axí fou fet rey d'Aragó, lo qual pres muller e morí sens fills.

A l'inici del següent capítol, la crònica explica l'elecció de Ramir I com a rei legítim d'Aragó:

Com feren rey en Aragó per elecció, constret a fer justícia. Any MLX·

La terra, cavallers e senyors muntiplicats e abigorats, acordaren que fessen rey en Aragó que no fos dels majors ni dels menors cavallers, mas dels mitjans; e que fos ab certs pactes e privilegis, estret a fer justícia e dret a les gents; e si no•u fahia, que totstemps hi hagués hun justícia que li fes tornar les coses a justícia e rahó. E axí en l'any V·de l'imperi del dit Anrich Terç, ço és, en l'any de Nostre Senyor·MLX·anys, elegiren e feren rey d'Aragó hun cavaller molt savi e bo que havia nom don Remiro..

\subsection{La comtessa de Tarragona}

El passatge de la Crònica universal de 1427 on apareix la llegenda de la comtessa de Tarragona té un interés especial perquè es tracta, tal com ja havia indicat Cortadellas $(2000 ; 2001)$, de l'únic testimoni de la llegenda que ens ha pervingut. La llegenda conté elements fantàstics, com ara la navegació marítima de la comtessa des de Tarragona fins a Anglaterra a sobre d'un mantell. També en recull d'altres, a ulls d'un lector actual, del tot inversemblants, com la donació del regne d'Anglaterra al comte de Tarragona. Segons Anna Cortadellas (2000), aquest relat fou concebut a mitjan segle XIV, mentre es desenvolupava un litigi entre Pere III i la diòcesi de Tarragona. L'objectiu de la llegenda, doncs, seria legitimar l'espoli del comtat de Tarragona que patí Robert d'Aculley, o Robert Bordet. Robert d'Aculley, cavaller normand i, segons sembla, bastard d'Enric I d'Anglaterra, va rebre el domini sobre el comtat de Tarragona de mans d'Oleguer, bisbe de Barcelona, i ostentà el títol de comte i príncep de Tarragona de 1129 a 1154 o 1157, fins que el succeí el seu fill Guillem. Ara bé, aquest i sa mare, Agnès, es van veure obligats a renunciar-ne als

REVISTA VALENCIANA DE FILOLOGIA / IV (2020) p. I37-I64 JACOB MOMPÓ NAVARRO

Falsament acusades d'adulteri / I 58 
drets a causa de les pressions judicials que efectuaren tant l'arquebisbat com el comtat de Barcelona. Al si d'aquesta pugna jurisdiccional, Guillem morí assassinat a Tortosa l'any 1168, fet que desencadenà l'assassinat de l'arquebisbe n'Hug de Cervelló a mans de Berenguer i Robert, germans de Guillem. Aquests consideraven l'arquebisbe el responsable de la pèrdua del comtat de Tarragona. Això no obstant, Agnès conservà, malgrat que només nominalment, el títol de comtessa de Tarragona fins la seua mort, l'any 1170 (Cortadellas i Vallès, 2000: 10-11).

Pel que fa a la llegenda, aquesta presenta elements comuns a les llegendes anteriors. En aquest cas, aprofitant l'absència del marit, un germà bastard d'aquest s'enamorà de la comtessa. Però, malgrat els esforços baronívols i cavallerosos que el germà del comte feia per guanyar-se l'amor de la cunyada, aquesta no sentí mai res per ell. Llavors, l'amant despitós envià una carta al seu germà en què acusava la comtessa d'haver comés adulteri amb un cavaller. Els soldats, seguint les indicacions que per carta envià el comte, es disposaren a llançar la comtessa a la mar; però ella s'encomanà a Déu i la Mare de Déu, llançà el seu mantell sobre l'aigua i puja a sobre. Miraculosament, el mantell va navegar fins a Anglaterra. En arribar a Tarragona, el comte es penedí d'allò que havia fet, donà el comtat a l'Església i es decidí a recórrer el món a la recerca de la seua esposa. El viatge del comte el dugué a Anglaterra, on es van repetir combats i justes semblants a d'altres llegendes que recull la crònica. Finalment, el protagonista es va guanyar el favor del rei i es va retrobar feliçment amb la seua estimada, a qui, recordem, poques línies abans havia condemnat a mort. Sota aquesta aurèola llegendària, doncs, camuflaria aquest espoli i el convertiria en una donació feta pel comte de Tarragona a l'Església. De fet, justament això és el que rubrica aquest capítol, així com la frase que introdueix la llegenda:

Com Terragona e lo comdat fou donat a la Església

En aquest temps, lo comte de Terragona donà Terragona e tota sa tinència a la Església. E fou aquesta, la causa:

REVISTA VALENCIANA DE FILOLOGIA / IV (2020) p. I37-I64 JACOB MOMPÓ NAVARRO Falsament acusades d'adulteri / I 59 
Lo comte de Barchinona tramés per misatger lo comte de Terragona a Roma, al papa. E com aquell se'n fo partit, hun germà bort que tenia lo dit comte enamorà's de ça muller, e fahia taules e molts torneigs per amor de ella. E ella no havia cura d'aquell, en tant que ell lo y dix e lo y féu dir; e aquella no havia cura d'aquell. E estant axí, vench nova que·l comte venia de la misatgeria e lo germà tench-se per perdut. E féu una letra al comte certificant-lo com la comtesa havia fet mal ab hun cavaller e, si no per ell, se'n fora anada ab aquell. E lo comte, rebuda la letra, crehent que son frare li deya veritat, féu una letra en la qual manà als officials de Terragona que, de continent, sens alguna triga la prenguesen e, que axí com estaria vestida, la lançassen en la mar. E aquells, rebuda la letra, ab gran dolor anaren a la comtessa, la qual trobaren vestida ab les pus belles robes d'aur que tenia, per goig de la venguda del comte, e diguen-li la causa per què venien; la qual respòs que complisen lo manament de lur senyor. E lavors aquells prengueren la comtessa e meteren-la en una barcha dins mar. E aquella, confiant en Déu e ab la Verge Maria, pres lo mantell e lançà'l en l'aygua e saltà sobre lo mantell, lo qual la sostench axí com si fos barcha e féu sa via tro que la perderen de vista; de la qual cosa, aquells qui eren en la barcha estigueren molt enmaravellats e, ab gran dol, tornaren-se'n a la ciutat.

E la comtessa anà aquell dia tant per mar que arribà en Anglaterra. E dos pescadors que estaven en una barcha, veren-la venir axí, fugiren cuydant-se que fos alguna fantasma. E aquella los cridà e los féu senyal que no haguessen por. E lavors aquells tornaren e reberen-la en la barcha, e portaren-la en casa de lur mare, que era bona dona e pofembra. E, de continent, la comtesa féu vendre lo seu mantell a la bona dona e féu-li’n comprar lli prim e seda, e obrà coxins e tovalloles e féu-les-li portar a vendre a la cort del rey, a la reyna e donzelles. E la reyna li demanà qui les havia obrades, e aquella li respòs que una dona qui estava en casa sua; e contà-li tota la manera de la sua venguda. E la reyna la pregà molt que la li menàs aquí. E lavors la comtessa vench a la cort de la reyna, e la reyna la pregà que aturàs aquí ab ella, la qual li respòs que li plahia, ab condició que no isqués fora la sua cambra. E axí fou fet e romàs aquí.

REVISTA VALENCIANA DE FILOLOGIA / IV (2020) p. I37-I64 JACOB MOMPÓ NAVARRO Falsament acusades d'adulteri / I60 
Ara tornem al comte. En aquell dia mateix, en la vesprada, lo comte vench en Terragona, e son frare fou fugit. E lo comte trobà tota la gent trista e demanà què era allò, los quals li dixeren lo gran peccat que havia fet en fer matar tal dona santa com era la comtesa. E digueren-li la maravella que li era esdevenguda en la mar; e lavors lo comte plorà agrament. E l'endemà, pres ab si alguns amichs singulars e anà-sse'n al bosch ab aquells, e aquí donà Terragona e tot lo condat a la Esgleya, e donà tots los diners e joyes que tenia a·quells que eren aquí ab ell. E votà denant aquells que jamés no cessaria de anar tro que hagués trobada la comtessa. E, ab gran dol, partí's de aquells e anà cercant la terra gran temps, que jamés no trobà rastre algú. E passant en Anglaterra, esdevench-se que, estant en la plaça, vench lo majordom del rey e dix-li: «Amich, pren aquexa canasta de pex e porta-la al palau». E aquell la pres e, com fou en la cuyna, lo cuyner li dix que aturàs aquí tant com se volgués. E romàs-se aquí a·judà al coch.

E esdevench-se que lo rey de Bretanya tramés misatgers al rey d'Anglaterra, que li donàs lo trahut de VII anys ho hagués cavaller que lo deffenés dins hun mes; en altra manera que s'aparellàs a la guerra. De la qual cosa lo rey hac gran desplaer, com no trobàs cavaller algú qui volgués combatre's per ell, en tant que perdé lo menjar. E com lo majordom digués al cuyner lo desplaer que lo senyor rey havia, dix lo comte: "Yo·m combatré per ell». E acostant-se lo terme, que ja no havien a passar sinó IIII dies, dix lo majordom al rey: «Sapiats, senyor, que ab lo vostre cuyner és hun hom que dix que ell se combatria per vós, lo qual me par ben forts e ha bon cors. E axí, senyor, pus no·n trobau altre, prenets aquest que no s'i perdrà res». E lavors lo rey féu-los venir davant e dix-li quin hom era. E aquell li respòs que era hom qui cercava ventura. E lo rey dix-li si-s volia combatre per ell, lo qual li respòs que hoc volenterosament. E lavors lo rey li donà les sues robes e aquell se mostrà en sos gets que era gran hom.

E com vench lo dia de la batalla, aquell anà al camp ab totes ses armes, a cavall, en continença de bon cavaller. E aquí fou l'altre cavaller. E combatent-se, lo comte passà la lança per los pits de aquell, que·l derroquà mort del cavall en terra. E lavors lo rey fonch quiti del trahut, e ab gran

REVISTA VALENCIANA DE FILOLOGIA / IV (2020) p. I37-I64 JACOB MOMPÓ NAVARRO Falsament acusades d'adulteri / I6I 
goig e festa tornaren-se'n al palau a dinar. E com vingué per pendre aiguamans, demanaren tovalloles. E la comtessa, passant devant la porta de la cambra del rey per donar les tovalloles, lo comte la vehé e mudà's tot, e ella axí metex. E com foren en taula, lo comte no menjà res, ne axí mateix la comtessa. E com foren levats de taula lo rey pres ha hun depart lo comte e dix-li per què s'era transmudat al pendre de la ayguamans, e per què no havia menjat al dinar; que, per la honor que li havia feta, que li digués si havia algú en la sua cort que li hagués fet algun desplaer, que ell li’n faria venjança aquella que ell ne volrria. E açò metex dix la reyna a la comtesa. E lavors dix lo comte al rey: «Senyor, jo vaig cercant per lo món gran temps ha una ventura, e és-me de parer que la he vuy vista en la vostra cort, de una dona que yo amava molt». E lavors lo rey entrà-sse'n en la cambra e dix a la reyna quala poria ésser la dona, e la reyna dix-li açò que la comtessa li havia dit. E lavors conegueren que la ventura que lo cavaller cercava era aquí. E lavors lo rey e la reyna affrontaren-los en una e, tantost que·s veren, abrassaren-se e caygueren esmortits. E com foren retornats, lo comte dix al rey com ell era lo comte de Terragona, e comtà-li tota l'aventura que li era esdevenguda, de què lo rey hac gran plaer com per tant honrat cavaller era estat deffés del trahut, e com aquell havia trobada la ventura en ça terra. E obtenguda licència del rey e de la reyna de venir aquells en Terragona per mostrar les meravelles que Déu les havia fetes, ab permissions, emperò, que feren al rey que tantost tornarien en Anglaterra. E lavors vengueren en Terragona e totes les gens hagueren-ne gran e inextimable goig e gran alegria. E com hagueren estat aquí hun temps, tornaren en Anglaterra. E aprés prochs dies, [lo] rey morí sens fills e lexà lo regne al comte de Terragona (ff. 181r-182v).

REVISTA VALENCIANA DE FILOLOGIA / IV (2020) p. I37-I64 JACOB MOMPÓ NAVARRO Falsament acusades d'adulteri / I 62 


\section{Bibliografia}

Aguilar, M. (2005) «La llegenda del bon comte i l'emperadriu: entre l'amor cortès i la política d'Estat», Journal of Catalan Studies, 8, pp. 63-76.

Alcoberro, A. (2003) «Mites i llegendes», Barcelona Quaderns d'Història, 9, pp. 135-148.

Beauvais, V. (1591) Speculi majoris Vincentii Burgundi praesulis Belvacensis... Tomus quartus, qui Speculum Historiale inscribitur, Venècia, Apud Dominicum Nicolinum.

Blasco Vallés, A. (2010) «Llamar al agua como experiencia poética en la cultura medieval», Cuadernos del CEMyR, 18, pp. 39-55.

Bohigas, P. (2001) Mirall d'una llarga vida. A Pere Bohigas, centenari, Antoni Badia i Margarit, Germà Colon i Josep Moran (eds.), Barcelona, Institut d'Estudis Catalans.

Carbonell, P. M. (1546) Chroniques de Espanya, Barcelona, Carles Amorós.

Cingolani, S. M. (2008) Libre dels reis, València, Publicacions de la Universitat de València.

Coll i Alentorn, M. (1949), "La llegenda d'Otger Cataló i els nou barons», Estudis Romànics,1, pp. 1-47.

- (1972) «Les cròniques universals catalanes», Butlletí de la Reial Acadèmia de Bones Lletres de Barcelona, 34, pp. 43-50.

Migne, J. P. (ed.). (1855) Magistri Petri Comestoris Historia Scholastica = Patrologiae cursus completus Tomus CXCVIII, París, Apud J. P. Migne editorem.

Cortadellas, A. (2000) «Sis llegendes inèdites de la historiografia catalana medieval», Llengua i Literatura. Revista anual de la Societat Catalana de Llengua i Literatura, 11, pp. 7-39.

- (2001) Repertori de llegendes historiogràfiques de la Corona d'Arago (segles XIII-XVI), Barcelona, Curial Edicions Catalanes.

Desclot, B. (1885) Crónica del Rey en Pere e dels seus antecessors passats, Barcelona, Imprenta de la Renaixensa.

Deyermonnd, A. (1995) La literatura perdida de la Edad Media castellana. Catálogo y estudio. Salamanca, Universidad de Salamanca.

FErrando, A. (1996) «Fortuna catalana d'una llegenda germànica. El tema de l'emperadriu d'Alemanya falsament acusada d'adulteri», Tilbert Dídac Schönberger, Axel Stegmann (eds.) Actes del dese col-loqui internacional de llengua i literatura catalanes, Frankfurt, 18-25 de setembre de 1994, Barcelona, Publicacions de l'Abadia de Montserrat, vol. II, pp. 197-216.

Ferrer Santanach, M. (2010) La traducció catalana medieval de les 'Dècades' de Titus Livi. Edició del llibre I (tesi doctoral), Barcelona, Universitat Autònoma de Barcelona.

— (2013) «Titus Livi a la 'Crònica universal' de 1425», Estudis Romànics, 35, pp. 427-433.

Galdeano Carretero, R. (ed.) (2017) Historia moral de Cathalunya: Llibre segon de la 'Història catalana', Barcelona, Institut d'Estudis Catalans.

Hinojosa, J. (1979), Crònica de Pere Maça, València, Universitat de Valencia.

REVISTA VALENCIANA DE FILOLOGIA / IV (2020) p. I37-I64

JACOB MOMPÓ NAVARRO

Falsament acusades d'adulteri / I 63 
Hirel-Wouts, S. (2006) «Le Justicia d'Aragon dans quelques chroniques de la couronne d'Aragon aux XIVe et XVe siècles : entre fiction juridique et représentation du pouvoir Royal». Cahiers d'études hispaniques médiévales, 29, vol. I, pp. 277-300.

Iвorra, J. (2000) Sumari d'Espanya per Berenguer de Puigpardines, València, Publicacions de la Universitat de Valencia.

Marineo Siculo, L. (1524) Crónica d'Aragon, València, En la casa y oficina dicha al Molí de la Rovella.

MenÉndez Pidal, R. (1923) «Relatos poéticos en las crónicas medievales: nuevas indicaciones». Revista de Filología Española, 10, pp. 329-372.

Mompó Navarro, Jacob (2019) Crònica Universal de 1427. Estudi i edició (tesi doctoral), València, Universitat de València.

Pattison, D. (1982) «The legend of the sons of Sancho el Mayor», Medium Aevum, 51, vol. I, pp. 35-54.

— (1997) «Leyendas épicas en las crónicas alfonsíes: enfoque de la cuestión», dins L’histoire et les nouveaux publics dans l'Europe médiévale (XIIIe-Xve siècle), París, Éditions de la Sorbonne, pp. 77-87.

Ramos, J. M. (1981) «Relatos poéticos en las crónicas medievales. Los hijos de Sancho III», Archivo de Filología Aragonesa, vols. XxviII-XXIX, pp. 313-334.

Saladrigues, R.; Torné, J. (2007) «El bon comte de Barcelona i la fundació de Poblet». Analecta Sacra Tarraconensia, 80, pp. 5-32.

Vagad, G. F. (1499) Crónica de Aragón, Saragossa, Pablo Hurus.

WARD, A. (2010) «Sancho el Mayor, la reina calumniada y los orígenes del reino de Castilla», José Antonio Jara Fuente, Georges Martin i Isabel Alfonso Antón (eds.), Construir la identidad en la Edad Media. Poder y memoria en la Castilla de los siglos VII a XV, Conca, Ediciones de la Universidad de Castilla-La Mancha, pp. 209-224.

Weiland, L. (1872) «Martini Oppaviensis Chronicon pontificum et imperatorum», dins Georgius Heinricus Pertz (ed.) Monumenta germaniae historica... Tomus XxII, Hannover, Impensiis Bibliopoli Aulici Hahniani, pp. 377-482.

Ximénez de Embún, T. (ed.) (1876) Historia de la Corona de Aragón: (la más antigua de que se tiene noticia) conocida generalmente con el nombre de Crónica de San Juan de la Peña, Saragossa, Imprenta del Hospicio.

REVISTA VALENCIANA DE FILOLOGIA / IV (2020) p. I37-I 64

JACOB MOMPÓ NAVARRO

Falsament acusades d'adulteri / I64 